\title{
RESEARCH
}

Open Access

\section{High remnant cholesterol level is relevant to diabetic retinopathy in type 2 diabetes mellitus}

\author{
Yongyan Shan®, Qian Wang, Yitong Zhang, Xuewei Tong, Shengdan Pu, Yuxin Xu and Xinyuan Gao*
}

\begin{abstract}
Background: Diabetic retinopathy (DR) is the primary oculopathy causing blindness in diabetic patients. Currently, there is increasing interest in the role of lipids in the development of diabetic retinopathy, but it remains controversial. Remnant cholesterol (RC) is an inexpensive and easily measurable lipid parameter; however, the relationship between RC and DR in type 2 diabetes mellitus (T2DM) has not been elucidated. This research investigates the relevance between RC levels and DR severity while building a risk prediction model about DR.

Methods: In this single-centre retrospective cross-sectional study. Each hospitalised T2DM patient had no oral lipidlowering drugs in the past three months, and coronary angiography showed epicardial coronary artery stenosis of less than 50\% and completed seven-field stereo photographs, fluorescein fundus angiography, and optical coherence tomography detection. The $\mathrm{RC}$ value is calculated according to the internationally recognised formula. Binary logistic regression was used to correct confounding factors, and the receiver operating characteristic (ROC) analysis was used to identify risk factors and assess the nomogram's diagnostic efficiency.

Results: A total of 456 T2DM patients were included in the study. The RC levels in the DR team was higher [0.74 $(0.60-1.12) \mathrm{mmo} / \mathrm{l}$ vs $0.54(0.31-0.83) \mathrm{mmol} / \mathrm{l} P<0.001]$ in the non-DR team. After adjusting for confounding

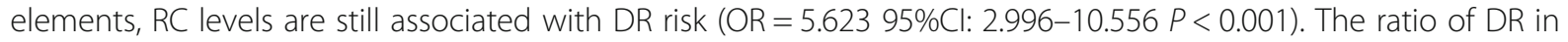
every stage (except mild non-proliferative diabetic retinopathy) and DME in the high RC level team were further increased compared to the low-level team (all $P<0.001$ ). After ROC analysis, the overall risk of DR was predicted by a nomogram constructed for RC, diabetes duration, and the neutrophil-lymphocyte ratio as $0.758(95 \% \mathrm{Cl} 0.714-$ $0.802 P<0.001)$.
\end{abstract}

Conclusions: High RC levels may be a potential risk factor for diabetic retinopathy, and the nomogram does better predict DR. Despite these essential findings, the limitation of this study is that it is single-centred and small sample size analysis.

Keywords: Diabetic retinopathy, Remnant cholesterol, Nomogram, NLR, DME, TyG-index, Type 2 diabetes mellitus

\footnotetext{
* Correspondence: m15124768260@163.com

Endocrinology department, The First Affiliated Hospital (FAH)for Harbin

Medical University(HMU), Harbin 150001, People's Republic of China
}

(C) The Author(s). 2022 Open Access This article is licensed under a Creative Commons Attribution 4.0 International License, which permits use, sharing, adaptation, distribution and reproduction in any medium or format, as long as you give appropriate credit to the original author(s) and the source, provide a link to the Creative Commons licence, and indicate if changes were made. The images or other third party material in this article are included in the article's Creative Commons licence, unless indicated otherwise in a credit line to the material. If material is not included in the article's Creative Commons licence and your intended use is not permitted by statutory regulation or exceeds the permitted use, you will need to obtain permission directly from the copyright holder. To view a copy of this licence, visit http://creativecommons.org/licenses/by/4.0/ The Creative Commons Public Domain Dedication waiver (http://creativecommons.org/publicdomain/zero/1.0/) applies to the data made available in this article, unless otherwise stated in a credit line to the data. 


\section{Introduction}

As the worldwide prevalence of diabetes mellitus increases, 463 million adults were diagnosed with diabetes in 2019, and according to this trend, there will be 700 million diabetes worldwide by 2045 [1]. Diabetic retinopathy (DR) is a prevalent neurovascular complication of diabetes mellitus and is the leading cause of blindness in the working-age generation [2]. Although glycemic levels, diabetes duration, microalbuminuria, and blood pressure levels are known risk elements for the development and advance of DR, current studies report that there may be other, as yet unknown, risk factors for the disease [3]. The association of dyslipidemia with DR has been thoroughly investigated. However, in many extensive studies, controversy still exists regarding the exact role of dyslipidemia in DR [4,5]. Perhaps, traditional lipid levels alone are inadequate, although a recent study shows that novel serum biomarkers of lipid profiles and inflammatory reactions are potentially related to DR [6].

Remnant cholesterol (RC) is the cholesterol content of triglyceride-rich lipoproteins, which is IDL and VLDL in the fasting state and the non-fasting state chylomicron remnants [7]. Current studies suggest that RC is derived from two pathways, the endogenous pathway is VLDL produced by the liver, and exogenously, chylomicron is made within the intestine. Triglycerides and chylomicrons in VLDL enter the bloodstream and are hydrolysed by lipoprotein lipase (LPL) at high speed, continuously producing smaller, denser residual lipoprotein particles. RC level assessment is inexpensive and convenient, perhaps providing valuable data for clinical management, and can be easily calculated using an established formula [8]. Recent studies have confirmed that RC positively affects a strong association with cardiovascular endpoints $[9,10]$. Whether remnant cholesterol also contributes to the development of microvascular disease in individuals with diabetes is an interesting question. Up to now, the relationship between $R C$ and DR in T2DM patients has not been researched. The present research explored the connection between $\mathrm{RC}$ levels and DR in Chinese T2DM patients.

\section{Methods}

\section{Study design and participants}

This retrospective observational cross-sectional study was undertaken in the First Affiliated Hospital of Harbin Medical University. According to the Declaration of Helsinki, the research was ratified by the Ethics Committee of the FAH in HMU. Consecutively selected hospitalised T2DM patients in the endocrinology and cardiology departments in the FAH for HMU between November 2018 and October 2021 were enrolled according to the following criteria. Inclusion criteria are:
(1) the diagnosis of T2DM was per 1999 WHO diagnostic criteria [11]; (2) no gender restrictions on participants over 18 years of age; (3) coronary angiography showed epicardial coronary artery stenosis of less than 50\%; (4) completed seven-field stereo photographs, fluorescein fundus angiography (FFA), and Optical Coherence Tomography (OCT) detection, and (5) blood lipid and other biochemical indicators were collected on the second day of admission, and the content was complete. Exclusion criteria are: (1) had taken fenofibrate or other oral lipidlowering drugs during the last three months; (2) definite cerebral infarction or cerebral revascularisation; (3) peripheral arterial occlusive disease; (4) any uncontrolled systemic disease other than sub-optimally controlled diabetes mellitus; (5) other ophthalmic diseases affect DR diagnosis, such as severe cataracts, and (6) any confirmed malignancies.

\section{Clinical data collection and laboratory analysis}

Demographic and physical data taken from the medical records included age, gender, diabetes duration, smoking, medical history, hypertension history, diabetic therapy, blood pressure, body mass index (BMI), and the diagnosis of diabetic peripheral neuropathy (DPN). Venous blood samples were collected after 1-night of fasting to determine Glycosylated Hemoglobin (HbA1c) by Ion Exchange High-Performance Liquid Chromatography (HPLC). The fasting blood glucose (FBG), total cholesterol (TC), triglycerides (TG), uric acid (UA), and creatinine ( $\mathrm{Cr}$ ) levels were determined using enzymatic methods. Fasting C-peptide was assessed using radioimmunoassay. Low-density lipoprotein cholesterol (LDL-C) and high-density lipoprotein cholesterol (HDL-C) levels were determined by homogeneous assays. An automated haematology analyser took white cell counts and differentials (model XT 2000i; Sysmex, Kobe, Japan). Microalbuminuria levels measurements were attained using a 24-h urine collection. According to the recommendation of dyslipidaemia guidelines [12], RC was computed as TC minus LDL-C and HDL-C; where eGFR $=141 * \min (\mathrm{Scr} / \kappa, 1)^{\alpha} \times \max (\mathrm{SCr} /$ $\mathrm{k}, 1)^{1.209} \times 0.993^{\mathrm{age}} \times$ gender $\times$ ethnic (For females, use the following values: gender $=1.018 ; \alpha=0.329 ; \kappa=0.7$; For males, use the following values: gender $=1 ; \alpha=0.411 ; \mathrm{K}=$ 0.9) [13]. The TyG index was calculated using [14]: Ln [fasting triglycerides $(\mathrm{mg} / \mathrm{dl}) \times$ fasting glucose $(\mathrm{mg} / \mathrm{dl})] / 2$. NLR values were obtained by dividing the neutrophil count by the lymphocyte count [15].

\section{Assessment of DR and DME}

Detection of the fundus was achieved by performing seven-field stereo photographs and FFA. The International Clinical Diabetic Retinopathy Disease Severity Scale was used [16] to grade DR. DR was divided into five stages of non-DR, non-proliferative diabetic 
retinopathy (mild, moderate, severe), and proliferative diabetic retinopathy (PDR). OCT was used to measure the thickness of macular fovea in eyes with macular oedema and determine the severity of the diabetic macular oedema using the International Clinical Diabetic Macular Oedema Disease Severity Scale.

\section{Statistical analysis}

Groups were divided according to the presence or absence of diabetic retinopathy. The statistical software SPSS 26.0 and "R language" statistical packages were used for the statistical analyses. The data's normalcy was assessed using the Shapiro-Wilk test. The continuous normality variables were introduced as the mean $\pm S D$ and evaluated using the Student's t-test. The skewed continuous variables were shown as the median (interquartile range, IQR) and were assessed using the MannWhitney $\mathrm{U}$ test. The Chi-square test was used to compare categorical variables. Spearman correlation and partial correlation analysis were used to analyse the connection between RC and DR stages. Spearman correlation analysis also examined the relationship between $\mathrm{RC}$ and other variables. The $P$-value of $P<0.05$ was defined as statistically significant.

The univariate binary logistic regression analyses were used to analyse the presence of DR as the dependent variable and risk elements of DR as independent variables. Those variables which were statistically significant in the univariate analysis but did not mutually interfere were included in the multiple binary regression analysis models. Outcomes of these regression analyses were assessed using ORs, 95\%CI, and $p$-values. HosmerLemeshow goodness of fit implementation was used in the optimal model in multivariate regression analysis to select variables to develop a nomogram of the prediction of DR occurrence. The receiver operating characteristic (ROC) analysis was used to identify risk factors and assess the nomogram's diagnostic efficiency.

The RC level was divided into three groups, according to tertile. The composition ratio of DR in each group, composition ratio at each DR stage, and DME composition ratio were analysed. Chi-square implementation was used to compare teams; $P<0.05$ was deemed statistically significant.

\section{Results}

The cohort of 456 subjects included 217 participants with DR and 239 without DR. The average age of the subjects was $53.54 \pm 12.13$, and the mean diabetes duration was $9.73 \pm 6.97$ years. The number and percentage of mild-NPDR, moderate-NPDR, severe-NPDR, PDR and DME in DR were 57 (26.3\%), 67 (30.9\%), 57 (26.3\%), $36(16.6 \%)$ and 55 (25.3\%), respectively. Age, diabetes duration, SBP, antihypertensive drugs, TC, RC, mAlb,
TyG-index, neutrophils, and NLR in the DR team were dramatically different from those in the non-DR team (all $P<0.05)$. Meanwhile, the eGFR level was lower $(P=$ $0.013)$, with no significant differences in other variables (all $P>0.05$, please see Table 1 ).

\section{Correlation between RC and other variables in the lipid profiles with stages of DR}

The correlation between $\mathrm{RC}$ and other variables in the lipid profiles (including TC, TG, LDL-C, HDL-C, ApoA, and ApoB) with the DR stages was assessed using Spearman correlation analysis. Table 2 shows that only $\mathrm{RC}$ and $\mathrm{TC}$ were correlated with the $\mathrm{DR}$ stages $(r=0.360 \quad P<0.001)$ and $(r=0.142 \quad P=0.002)$, respectively. Even after controlling TC by partial correlation analysis, $R C(r=0.298 P<0.001)$ was still correlated with DR stages. In the univariate analysis, the risk factors of DR, age, diabetes duration, DNP, oral antihypertensive drugs, systolic blood pressure, TC, RC, mAlb, TyG, and NLR were statistically significant. After adjusting confounding factors using binary logistic regression analysis, $\mathrm{RC}(\mathrm{OR}=5.623 \quad 95 \% \mathrm{CI}$ : 2.996-10.556 $P<0.001$ ) was still a risk factor for DR, as shown in Tables 3 and S1. Moreover, the variables of NLR(OR $=1.742$ 95\% CI: $1.218-2.493 P=0.002)$ and diabetes duration $(\mathrm{OR}=1.25095 \% \mathrm{CI}: 1.064-1.496 \mathrm{P}=$ $0.007)$ were also statistically significant in the multivariate analysis.

\section{RC, NLR, and diabetes duration predicted value of DR}

The multivariate regression analyses derived the nomogram of DR prediction in Fig. 1, composed of RC, NLR, and diabetes duration. The ROC analysis highlights the data scope, with the range of the ROC curve (AUC) for RC, NLR, diabetes duration, and the nomogram of 0.714 (95\%CI $0.672-0.755 ; p<0.001), 0.597 \quad(95 \%$ CI $0.545-$ 0.649; $P<0.001$ ), 0.672 (95\%CI $0.623-0.721 ; P<0.001$ ), and 0.758 (95\%CI $0.714-0.802 P<0.001)$, independently (Fig. S1).

\section{The relationship between RC level and DR, every stage of DR and DME}

The RC levels were divided into three teams as per tertile; Tertile1 team $(<0.52 \mathrm{mmol} /, N=150)$, Tertile 2 team $(0.52-0.83 \mathrm{mmo} / \mathrm{l}, N=152)$ and Tertile3 group ( $>0.83 \mathrm{mmol} / \mathrm{l}, N=154)$. In contrast with the Tertile 1 team, the ratio of DR, moderate-NPDR, severeNPDR, PDR, and DME in the Tertile3 group increased significantly (all $P<0.01$ ), but the ratio of mild-NPDR yielded no statistically significant difference (Fig. 2). 
Table 1 Characteristics of the non-DR group and DR group

\begin{tabular}{|c|c|c|c|c|}
\hline Variables & All $(n=456)$ & Non-DR $(n=239)$ & $\mathrm{DR}(n=217)$ & $P$-value \\
\hline Age (years) & $53.54 \pm 12.13 / 55(44-63)$ & $53(40-62)$ & $57(47-64)$ & $0.009^{* *}$ \\
\hline Male gender, n (\%) & $292(64)$ & $161(65.2)$ & $131(62.7)$ & 0.579 \\
\hline Diabetes duration (years) & $9.73 \pm 6.97 / 9(4-15)$ & $7(3-12)$ & $11(6-16)$ & $0.001^{* *}$ \\
\hline Hypertension, n (\%) & $232(46.4)$ & $105(42.5)$ & $127(50.2)$ & 0.085 \\
\hline Current smoking, n (\%) & $150(32.9)$ & $89(36)$ & $61(29.2)$ & 0.121 \\
\hline DNP, n (\%) & $175(38.5)$ & 79 (33.2) & $96(44.2)$ & 0.027 \\
\hline $\mathrm{BMI}\left(\mathrm{kg} / \mathrm{m}^{2}\right)$ & $25.6(23.92-27.95)$ & $25.39(23.84-27.39)$ & $25.6(23.98-28.09)$ & 0.929 \\
\hline $\mathrm{SBP}(\mathrm{mmHg})$ & $140(126-150)$ & $137(123-150)$ & $140(130-154)$ & $0.007^{*}$ \\
\hline $\mathrm{DBP}(\mathrm{mmHg})$ & $80(74-90)$ & $80(72-88)$ & $81(75-90)$ & 0.067 \\
\hline $\mathrm{FBG}(\mathrm{mmol} / \mathrm{L})$ & $8.44(6.88-10.61)$ & $8.2(6.79-10.54)$ & $8.59(7.04-10.71)$ & 0.163 \\
\hline $\mathrm{HbA1c}(\%)$ & $8.4(7.2-9.6)$ & $8.2(7.1-9.5)$ & $8.5(7.6-9.8)$ & 0.076 \\
\hline $\mathrm{HbA1c}(\mathrm{mmol} / \mathrm{mol})$ & $68(55-81)$ & $66(54-80)$ & $69(60-84)$ & 0.057 \\
\hline Fasting C-Peptide (ng/ml) & $1.5(1.0-2.2)$ & $1.55(1.0-2.3)$ & $1.5(1.0-2.15)$ & 0.426 \\
\hline Neutrophil $\left(\times 10^{9} / \mathrm{L}\right)$ & $3.71(3.05-4.45)$ & $3.48(2.96-4.41)$ & $3.85(3.17-4.5)$ & $0.01^{*}$ \\
\hline Lymphocyte $\left(\times 10^{9} / \mathrm{L}\right)$ & $2.22(1.78-2.64)$ & $2.26(1.87-2.69)$ & $2.17(1.73-2.56)$ & 0.053 \\
\hline Monocyte $\left(\times 10^{9} / \mathrm{L}\right)$ & $0.38(0.31-0.45)$ & $0.38(0.3-0.45)$ & $0.38(0.31-0.44)$ & 0.31 \\
\hline $\mathrm{TC}(\mathrm{mmol} / \mathrm{L})$ & $5.02(4.42-5.74)$ & $4.96(4.24-5.58)$ & $5.13(4.58-5.96)$ & $0.000^{* *}$ \\
\hline $\mathrm{TG}(\mathrm{mmol} / \mathrm{L})$ & $2.18(1.4-3.43)$ & $2.12(1.43-3.2)$ & $2.31(1.35-3.59)$ & 0.286 \\
\hline $\mathrm{HDL}-\mathrm{C}(\mathrm{mmol} / \mathrm{L})$ & $1.15(0.99-1.3)$ & $1.11(0.99-1.28)$ & $1.16(1.00-1.325)$ & 0.496 \\
\hline $\mathrm{LDL}-\mathrm{C}(\mathrm{mmol} / \mathrm{L})$ & $3.09(2.66-3.58)$ & $3.14(2.65-3.59)$ & $3.05(2.66-3.55)$ & 0.822 \\
\hline APOA (g/L) & $1.26(1.13-1.39)$ & $1.25(1.14-1.39)$ & $1.21(1.11-1.40)$ & 0.981 \\
\hline APOB $(g / L)$ & $1.03(0.87-1.21)$ & $1.035(0.84-1.2)$ & $1.03(0.9-1.22)$ & 0.2 \\
\hline $\mathrm{RC}(\mathrm{mmol} / \mathrm{L})$ & $0.65(0.45-0.99)$ & $0.54(0.31-0.83)$ & $0.74(0.60-1.12)$ & $0.000^{* *}$ \\
\hline TyG-index & $9.62 \pm 0.78$ & $9.52 \pm 0.73$ & $9.72 \pm 0.82$ & $0.006^{*}$ \\
\hline NLR & $1.64(1.36-2.03)$ & $1.60(1.30-1.93)$ & $1.69(1.41-2.26)$ & $0.000^{* *}$ \\
\hline Uric Acid $(\mu \mathrm{mol} / \mathrm{L})$ & $329.3(280.4-393.8)$ & $326.3(276.6-395)$ & $330.8(286.05-393.7)$ & 0.644 \\
\hline Creatinine ( $\mu \mathrm{mol} / \mathrm{L})$ & $61.3(50.6-70.5)$ & $60.5(50.45-70.13)$ & $62.3(51.1-72.4)$ & 0.384 \\
\hline eGFR $\left(\mathrm{ml} / \mathrm{min} / 1.73 \mathrm{~m}^{2}\right)$ & $108.6(97.68-121.03)$ & $110.96(98.24-123.10)$ & $106.27(96-117.95)$ & 0.013 \\
\hline mAlb (mg/24h) & $20.31(19.76-33.63)$ & 19.95 (19.57-23.56) & $20.71(19.95-56.53)$ & $0.000^{* *}$ \\
\hline Metformin, n (\%) & $277(60.7)$ & $149(60.3)$ & $128(61.2)$ & 0.841 \\
\hline DPP-IV inhibitor, n (\%) & $189(41.4)$ & $98(39.7)$ & $91(43.5)$ & 0.404 \\
\hline Acarbose, n (\%) & $68(15.3)$ & $38(15.9)$ & $30(14.6)$ & 0.712 \\
\hline Insulin, n (\%) & $139(30.5)$ & $72(29.1)$ & $67(32.1)$ & 0.502 \\
\hline Anitihypertensive drugs, n (\%) & $159(34.9)$ & $76(30.8)$ & $83(39.7)$ & $0.046^{*}$ \\
\hline
\end{tabular}

Abbreviations: $D R$ diabetic retinopathy, $D P N$ diabetic peripheral neuropathy, $B M I$ body mass index, $S B P$ systolic blood pressure, $D B P$ diastolic blood pressure, $F B G$ Fasting blood glucose, $A P O A$ apolipoprotein $A, A P O B$ apolipoprotein $B, T C$ total cholesterol, $T G$ triglyceride, $H D L-C$ high-density lipoprotein cholesterol, $L D L-C$ lowdensity lipoprotein cholesterol, $R C$ remnant cholesterol, eGFR estimated glomerular filtration rate, $H b A 1 c$ glycosylated hemoglobin, TyG-index triglyceride glucose index, NLR neutrophil to lymphocyte ratio, DR diabetic retinopathy, DPP-IV dipeptidyl peptidase-IV, mAlb microalbuminuria

Notes: Data are expressed as mean $\pm \mathrm{SD}$, percentages, or as medians (IQR); $p$-values were compared by independent t-test, Mann-Whitney $\mathrm{U}$ test, or Chi-square test as appropriate. ${ }^{*} P<0.05, * * P<0.001$

\section{Relationship between RC and other potential risk factors of DR}

The correlation between RC and other potential risk factors of DR was assessed using spearman correlation analysis, with the results suggesting that BMI $(r=0.104)$, HbA1c $(r=0.101)$, TC $(r=0.559)$, TG $(r=0.477)$, LDL-C $(r=0.136)$, APOB $(r=0.398)$, UA $(r=0.15)$, mAlb $(r=$
$0.179)$ and TyG-index $(r=0.488)$ were positively correlated with RC (all $P<0.05$, Table 4).

\section{Discussion}

The current research findings offer novel evidence that the circulating level of $\mathrm{RC}$ is positively correlated with the occurrence and severity of DR (Table 3, Fig. 3). RC 
Table 2 The correlation between stages of DR and the following lipid profiles

\begin{tabular}{|c|c|c|c|c|}
\hline \multirow[t]{2}{*}{ Variables } & \multicolumn{2}{|c|}{ Spearman Correlation Analysis } & \multicolumn{2}{|c|}{ Partial Correlation Analysis } \\
\hline & $\bar{r}$ & $P$-value & $\bar{r}$ & $P$-value \\
\hline $\mathrm{RC}(\mathrm{mmol} / \mathrm{L})$ & 0.360 & $0.000^{* *}$ & - & - \\
\hline $\mathrm{TC}(\mathrm{mmol} / \mathrm{L})$ & 0.142 & $0.002^{*}$ & $0.289^{\mathrm{a}}$ & $0.000^{* *}$ \\
\hline $\mathrm{TG}(\mathrm{mmol} / \mathrm{L})$ & 0.068 & 0.148 & $0.324^{b}$ & $0.000^{* *}$ \\
\hline LDL-C (mmol/L) & -0.016 & 0.736 & $0.332^{c}$ & $0.000^{* *}$ \\
\hline $\mathrm{HDL}-\mathrm{C}(\mathrm{mmol} / \mathrm{L})$ & 0.054 & 0.254 & $0.327^{d}$ & $0.000^{* *}$ \\
\hline $\mathrm{APOA}(\mathrm{g} / \mathrm{L})$ & 0.003 & 0.947 & $0.334^{\mathrm{e}}$ & $0.000^{* *}$ \\
\hline $\mathrm{APOB}(\mathrm{g} / \mathrm{L})$ & 0.066 & 0.165 & $0.329^{f}$ & $0.000^{* *}$ \\
\hline
\end{tabular}

Abbreviations: $A P O A$ apolipoprotein $\mathrm{A}, A P O B$ apolipoprotein $\mathrm{B}, R C$ Remnant cholesterol, $T C$ total cholesterol, $T G$ triglycerides, $L D L-C$ low-density lipoprotein cholesterol, $H D L-C$ high-density lipoprotein cholesterol, $A P O A$ apolipoprotein A, APOB apolipoprotein B

Notes: associations between serum lipid profile and stages of DR by Spearman correlation analysis and the association between RC and stages of DR by partial correlation analysis ${ }^{a}$ Adjusted for TC; ${ }^{\text {b }}$ Adjusted for TG; ${ }^{c}$ Adjusted for LDL-C; ${ }^{d}$ Adjusted for HDL; ${ }^{e} A d j u s t e d$ for APOA; ${ }^{f} A d j u s t e d$ for APOB. ${ }^{*} P<0.05,{ }^{* *} P<0.001$

may be another risk factor for DR, in addition, to complete cholesterol, low-density lipoprotein, triglycerides, and traditional blood lipid profiles. However, the contribution of high-level RC in mild DR was minor, and the damage of $\mathrm{RC}$ to microvascular environments in diabetic patients may be a chronic and long-term process [17].

It is well known that most T2DM patients have relatively high BMIs, insulin resistance, and insulin secretion disorders [18], increasing the number of cholesterol-rich VLDL residual particles [19]. TyGindex is a proxy for insulin resistance and is highly correlated with the gold standard hyperinsulinemiaorthoglycemic clamp [20], which can be a good assessment of insulin resistance in patients. It has been reported that $\mathrm{RC}$ was correlated with insulin resistance [21]. In the current study, TyG-index is associated with $\mathrm{RC}(\mathrm{r}=0.488 \quad P<0.001)$. Insulin resistance leads to elevated RC levels, which may be involved in the occurrence of DR [22].

Table 3 The association between $R C$ value and DR

\begin{tabular}{|c|c|c|c|c|c|c|}
\hline \multirow[t]{2}{*}{ Factors } & \multicolumn{3}{|c|}{ Univariate model } & \multicolumn{3}{|c|}{ Multivariate model } \\
\hline & OR & $95 \% \mathrm{Cl}$ & $P$-value & OR & $95 \% \mathrm{Cl}$ & $P$-value \\
\hline Age, per10y increase & 1.221 & $1.051-1.418$ & $0.009^{* *}$ & 1.002 & $0.981-1.022$ & 0.880 \\
\hline Diabetes duration, per $1 y$ increase & 1.357 & $1.184-1.555$ & $0.000^{* *}$ & 1.072 & $1.036-1.110$ & $0.000^{* *}$ \\
\hline DPN, yes or no & 1.561 & $1.067-2.284$ & 0.022 & 1.201 & $0.770-1.873$ & 0.419 \\
\hline Anitihypertensive drugs, yes or no & 0.6 & $0.458-0.994$ & 0.046 & 1.062 & $0.666-1.690$ & 0.800 \\
\hline SBP, per10mmHg increase & 1.16 & $1.043-1.289$ & $0.006^{*}$ & 1.004 & $0.992-1.018$ & 0.498 \\
\hline FBG, per $1 \mathrm{mmol} / \mathrm{L}$ increase & 1.04 & $0.976-1.108$ & 0.228 & & & \\
\hline $\mathrm{HbA} 1 \mathrm{c}$ per $1 \%$ increase & 1.078 & $0.971-1.197$ & 0.159 & & & \\
\hline Uric acid per $1 \mu \mathrm{mol} / \mathrm{l}$ increase & 1.00 & $0.998-1.001$ & 0.61 & & & \\
\hline $\mathrm{TC}$, per $1 \mathrm{mmol} / \mathrm{L}$ increase & 1.367 & $1.145-1.632$ & $0.000^{* *}$ & 0.936 & $0.731-1.198$ & 0.598 \\
\hline $\mathrm{TG}$, per $1 \mathrm{mmol} / \mathrm{L}$ increase & 1.087 & $0.995-1.187$ & 0.064 & & & \\
\hline HDL-C, per $1 \mathrm{mmol} / \mathrm{L}$ increase & 1.315 & $0.676-2.556$ & 0.42 & & & \\
\hline LDL-C, per $1 \mathrm{mmol} / \mathrm{L}$ increase & 1.007 & $0.793-1.279$ & 0.956 & & & \\
\hline eGFR, per1 $10^{-1-1}\left(\mathrm{ml} / \mathrm{min} / 1.73 \mathrm{~m}^{2}\right)$ increase & 0.93 & $0.844-1.026$ & 0.147 & & & \\
\hline $\mathrm{mAlb}>30 \mathrm{mg} / 24 \mathrm{~h}$, yes or no & 1.003 & $1.001-1.005$ & $0.003^{*}$ & 1.334 & $0.814-2.185$ & 0.252 \\
\hline TyG-index per1 increase & 1.393 & $1.095-1.772$ & 0.007 & 0.766 & $0.554-1.059$ & 0.106 \\
\hline $\mathrm{RC}$, per $1 \mathrm{mmol} / \mathrm{L}$ increase & 6.823 & $4.011-11.609$ & $0.000^{* *}$ & 5.623 & $2.996-10.556$ & $0.000^{* *}$ \\
\hline NLR per1 increase & 1.801 & $1.310-2.477$ & $0.000^{* *}$ & 1.598 & $1.121-2.279$ & $0.01^{*}$ \\
\hline
\end{tabular}

Abbreviations: $D R$ diabetic retinopathy, DPN diabetic peripheral neuropathy, $B M I$ body mass index, SBP systolic blood pressure, FBG Fasting blood glucose, HbA1C glycosylated hemoglobin, TC total cholesterol, $T G$ triglyceride, $H D L-C$ high-density lipoprotein cholesterol, $L D L-C$ low-density lipoprotein cholesterol, $A P O A$ apolipoprotein A, APOB apolipoprotein B, eGFR estimated glomerular filtration rate, TyG-index triglyceride glucose index, SBP systolic blood pressure, UA Uric acid, $N L R$ Neutrophil-Lymphocyte ratio, TyG-index triglyceride glucose index, $m A / b$ microalbuminuria Notes: Binary Logistic Regression Analysis. ${ }^{*} P<0.05,{ }^{* *} P<0.001$ 


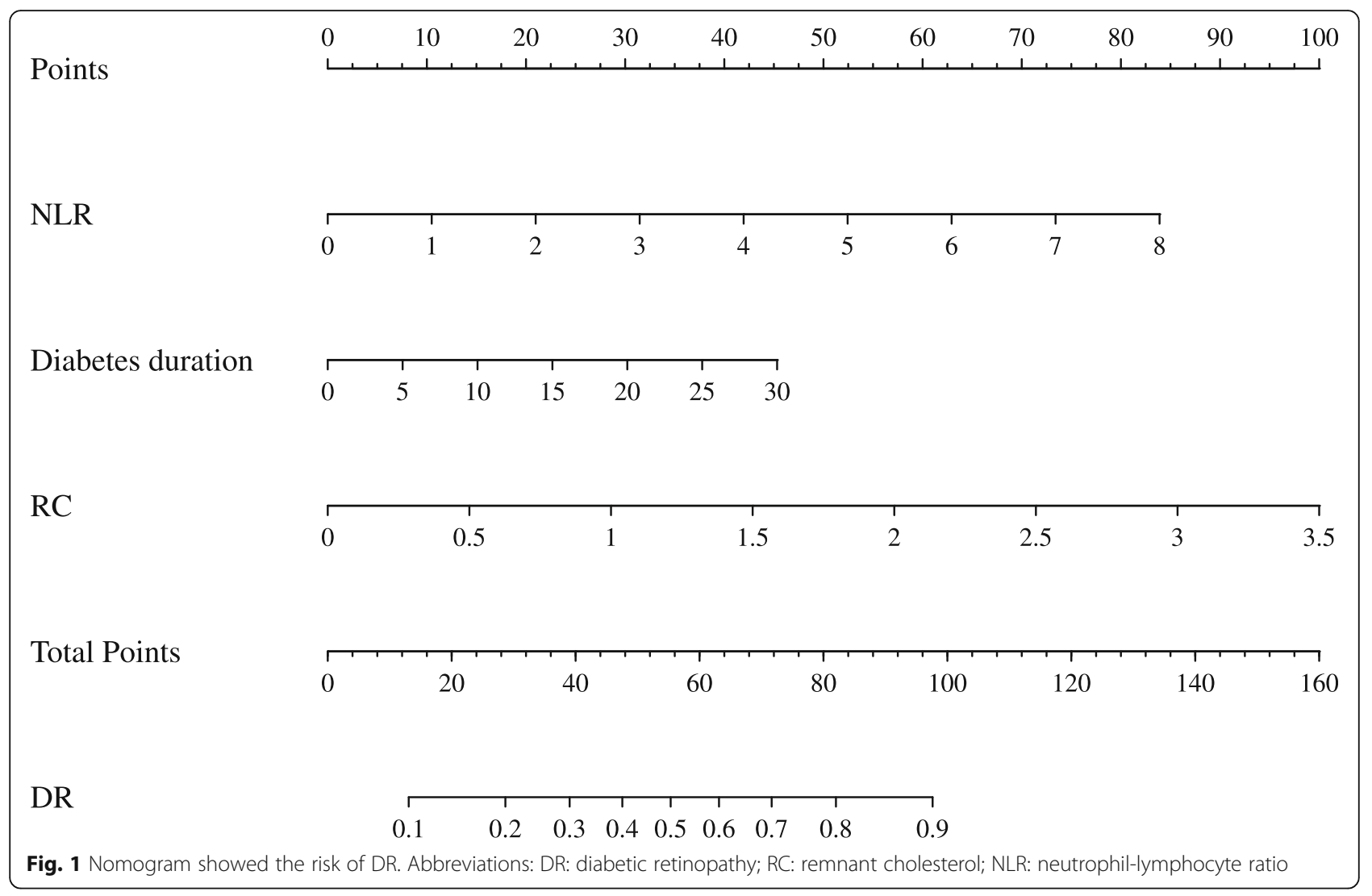

It is widely believed that NLR can be used as an inflammatory marker for some non-infectious diseases [23, 24]. In this study, there is a significant difference between the DR group and the non-DR team [1.6 (1.3-1.93) vs1.69 (1.412.76) $P<0.01]$, which was consistent with the results of Wang et al. [25]. In addition, a low-grade inflammatory response is one of the recognised pathogenesis of DR. It is associated with oxidative stress, high expression of inflammatory factors and the formation of advanced glycation end products (AGEs). Notably, RC can also trigger an inflammatory response, causing damage to the vascular endothelium [8]. Animal experiments have confirmed that $\mathrm{RC}$ particles easily enter the intima of the artery due to their particles size and composition characteristics, do not readily diffuse back into the blood, and can be directly ingested by macrophages [26]. Macrophages promote lipid decomposition, and triglyceride-rich lipoproteins (TGRLs) generate core components, especially high levels of fatty acids and saturated fatty acids, which combine with toll-like receptors 4 and 2 , induce inflammasome activation, promote interleukin- $1 \beta$ secretion, and amplify inflammatory effects [27]. Varbo's clinical study on the relationship between RC and LDL and ischemic heart disease and lowgrade systemic inflammation reported that only elevated $\mathrm{RC}$ levels had a causal relationship with low-grade systemic inflammation [28]. In the current study, RC and NLR were higher in the DR group, but there was no apparent correlation. The relationship between the two needs to be further validated by large sample size studies.

Additionally, there was a dynamic relationship between RC and UA $(r=0.15 P<0.001)$. Some studies have reported that a high standard of UA is closely associated with oxidative stress and inflammation [29]. Other studies suggested that UA can protect vascular endothelium, which may be caused by the antioxidant effect of UA concentrations in a particular range [30]. However, inflammatory responses can be stimulated [31]. Notably, a sizeable cross-sectional study of a rural Chinese populace reported that high uric acid levels might be associated with various blood lipids [32]. Do increased UA levels contribute to the RC reduction? Investigating the relationship between the two is worthy of further research.

$\mathrm{RC}$ may be a risk factor for both macrovascular and microvascular diseases in diabetes patients. A large cohort study found that residual cholesterol, rather than LDL-C, may be the primary cause of arteriosclerotic cardiovascular disease. The relative risk of major adverse cardiovascular events increased by $21 \%$ for every $10 \mathrm{mg} /$ $\mathrm{dL}$ increase in residual cholesterol levels (about 0.26 $\mathrm{mmol} / \mathrm{L}$ ) [10], and a second cross-sectional study in China showed that RC was related to the risk of 


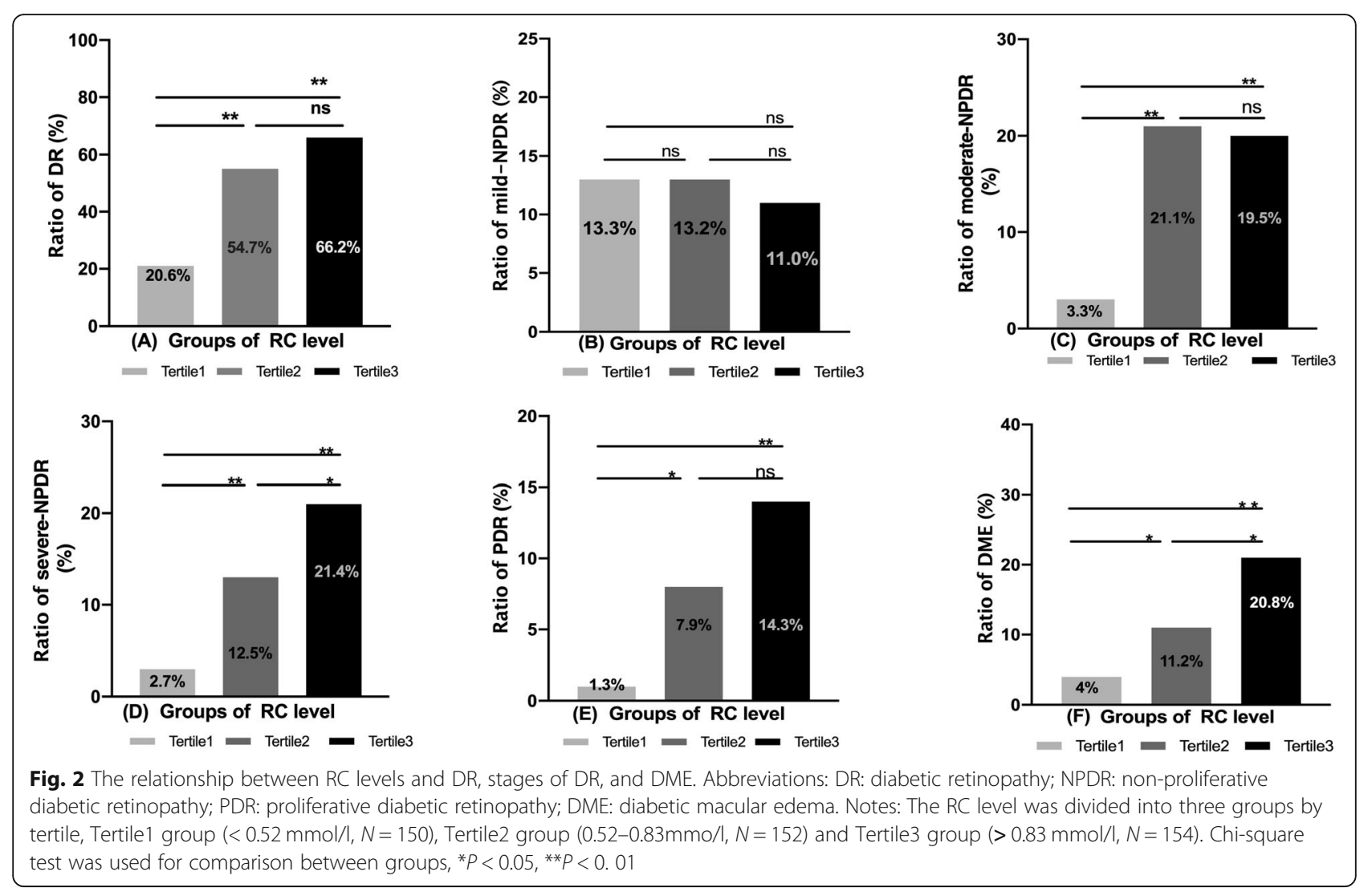

cardiovascular death in T2DM patients with newly diagnosed stage 3-5 DN [33]. Furthermore, a recent cohort study suggests that $\mathrm{RC}$ is associated with visionthreatening DR in type 1 diabetes [34]. The present study selected type 2 diabetic patients without coronary heart disease to avoid patients affected by the relationship between $\mathrm{RC}$ and diabetic retinopathy. Finally, in this study, microalbuminuria was related to RC $(r=0.179 P<0.001)$, but the relationship between $\mathrm{RC}$ and DR was not disturbed after adjusting for the 24-h microalbumin variable using binary logistic regression (Tables 4 and S2).

The two primary visual-threatening complications of diabetic retinopathy are the proliferative phase of retinal neovascularisation and macular oedema, leading to the destruction of the central blood-retinal obstacle. In this study, the incidence of PDR and DME increased significantly in the high RC level group (Fig. 2). Related metaanalysis and cross-sectional studies suggest that the occurrence of DME is closely associated with high triglyceride levels [35], and the current study found that RC correlates with TG $(\mathrm{r}=0.447 P<0.001)$. RC may be a risk factor masked by TG for DME and PDR. There is evidence of considerable residual risk of cardiovascular events even after LDL-C reduction or HDL-C increase to recommended concentrations with statins and other lipid-lowering agents due, in part, to elevated RC levels [36]. Similarly, the elevation of RC levels is important for preventing and delaying DME and PDR.

The nomogram can predict the risk of disease occurrence and has attracted more attention due to its simple, intuitive, and reference value. Therefore, RC, NLR, and diabetes duration were selected and contributed to the most stable model in multivariate logistic regression analysis and resulted in the predicted risk of DR nomogram. Diagnostic efficiency was 0.758 (95\%CI 0.714 $0.802 P<0.001)$. For communities or hospitals without facilities for fundus examination, physicians can use this predictive model to screen people at higher risk of DR.

Although the relationship between HbA1c and DR is widely recognised $[37,38]$, the current study found no significant difference in HbA1c between the DR group and the non-DR participants [8.5 (7.6-9.8) vs 8.2 (7.19.5) $P=0.076]$. Those participants that were hospital inpatients often had poorly controlled glycemic levels, which may have caused this discrepancy. Interestingly, a similar phenomenon was also reported in other studies $[39,40]$. It should be acknowledged that selection bias is challenging to avoid when hospital inpatients are participants in research studies.

The effects of RC on patients with type 2 diabetes may involve the imbalance of oxidative and antioxidant 
Table 4 The correlation between RC value and other potential risk factors of DR

\begin{tabular}{lll}
\hline Variables & \multicolumn{2}{l}{ Spearman Correlation Analysis } \\
\cline { 2 - 3 } & $\mathbf{r}$ & $\boldsymbol{P}$-value \\
\hline Age (years) & -0.007 & 0.884 \\
Diabetes duration (years) & 0.068 & 0.149 \\
BMl (kg/m²) & 0.104 & $0.027^{*}$ \\
Fasting C-pepide $(\mathrm{ng} / \mathrm{ml})$ & 0.007 & 0.885 \\
HbA1c (\%) & 0.101 & $0.031^{*}$ \\
TC (mmol/L) & 0.559 & $0.000^{* *}$ \\
TG (mmol/L) & 0.447 & $0.000^{* *}$ \\
HDL-C (mmol/L) & 0.085 & 0.069 \\
LDL-C (mmol/L) & 0.136 & $0.002^{*}$ \\
APOA (g/L) & 0.033 & 0.49 \\
APOB (g/L) & 0.398 & $0.000^{*}$ \\
eGFR (ml/min/1.73m $\left.{ }^{2}\right)$ & -0.004 & 0.927 \\
UA ( $\mu \mathrm{mol} / \mathrm{L})$ & 0.15 & $0.000^{* *}$ \\
mAlb (mg/24 h) & 0.179 & $0.000^{* *}$ \\
NLR & 0.035 & 0.463 \\
TyG-index & 0.488 & $0.000^{* *}$ \\
\hline Ab & &
\end{tabular}

Abbreviations: $D R$ diabetic retinopathy, $B M I$ body mass index, HbA1c glycated hemoglobin, $T C$ total cholesterol, $T G$ triglyceride, HDL high-density lipoprotein, $L D L$ low-density lipoprotein, $A P O A$ apolipoprotein $A, A P O B$ apolipoprotein $B$, eGFR estimated glomerular filtration rate, TyG-index triglyceride glucose index, UA Uric Acid, NLR Neutrophil-Lymphocyte ratio, TyG-index triglyceride glucose index, mAlb microalbuminuria

Notes: Spearman Correlation Analysis. ${ }^{*} P<0.05,{ }^{* *} P<0.001$

capacity [27], RC is involved in the damage of the vascular endothelium [8] and the activation of the inflammatory response. Also, insulin resistance may be involved in the increase of RC [21]. These effects have been confirmed in previous studies on macrovascular complications in T2DM patients. However, the correlation between RC and DR was confirmed in this study based on the hospitalisation of type 2 diabetes mellitus for the first time.

\section{Study advantages and limitations}

The advantage is that patients with type 2 diabetes with cardiovascular disease were excluded in this study in order to further explore the correlation between the occurrence and severity of RC and DR. However, also some limitations in this research. For example, the study was undertaken in a single-centre, with the observational design based on a relatively cross-sectional analysis with an insufficient sample size. Notably, the prevalence of dyslipidemia and other risk elements in the Asian population was similar to other extensive contemporary tests and real-world registries involving ethnic groups [41, 42], which may support the generality of the study outcomes. Secondly, RC is correlated with DR, but the causal relationship between $\mathrm{RC}$ and $\mathrm{DR}$ cannot be proven. Thirdly, to exclude the influence of lipidlowering drugs on lipid profile metabolism, subjects in this study had not taken any lipid-lowering drugs orally in recent three months. This study cannot differentiate whether lipid-lowering oral medicines impact $\mathrm{RC}$ levels. Besides, the DR risk nomogram only has internal validation, and its diagnostic efficacy may be reduced without an external warranty.

\section{Conclusions}

In patients with $\mathrm{T} 2 \mathrm{DM}$, high RC levels positively correlate with the occurrence and severity of DR. These striking findings suggested that DR may not only be affected by high blood glucose levels but also influenced by a complex lipid profile. Clinicians and patients could easily predict the occurrence of DR through a nomogram considering RC, NLR, and diabetes duration. Insulin resistance interventions may help reduce $\mathrm{RC}$ level and control DR risk, which must be investigated in future multicenter or community-based prospective cohort studies.

\section{Abbreviations}

DR: Diabetic retinopathy; DPN: Diabetic peripheral neuropathy; BMI: Body mass index; SBP: Systolic blood pressure; DBP: Diastolic blood pressure; FBG: Fasting blood glucose; APOA: Apolipoprotein A; APOB: Apolipoprotein B; TC: Total cholesterol; TG: Triglyceride; HDL-C: High-density lipoprotein cholesterol; LDL-C: Low-density lipoprotein cholesterol; RC: Remnant cholesterol; eGFR: Estimated glomerular filtration rate; HbA1c: Glycosylated hemoglobin; TyG-index: Triglyceride glucose index; NLR: Neutrophil to lymphocyte ratio; DPP-IV: Dipeptidyl peptidase-IV; mAlb: Microalbuminuria; ROC: Receiver operating characteristic; AUC: Area under the curve;

DME: Diabetic macular oedema

\section{Supplementary Information}

The online version contains supplementary material available at https://doi. org/10.1186/s12944-021-01621-7.

Additional file 1: Table S1 The association between $R C$ value and DR. Table S2 Effects of other variables on the relationship between RC and DR.

Additional file 2: Fig. S1 ROC Curve for RC, NLR, DM Duration and Risk of DR Nomogram.

\section{Acknowledgments}

I am indebted to my tutor and team members for their efforts and support.

\section{Authors' contributions}

Conception and design analysis and data interpretation: XYG, YYS. The manuscript was drafted by: YYS, XYG, QW. Statistical analysis: YTZ, XWT. Data collation: SDP, XYX. Critical revision of the manuscript for important intellectual content: all authors. The authors read and approved the final manuscript.

\section{Funding}

The research was supported through grants from the Fund of Scientific Research Innovation of the FAH in HMU (grant number 2020 M27, China).

Availability of data and materials

The authors declare the data related to this study can be available from the corresponding author upon reasonable request. 


\section{Declarations}

\section{Ethics approval and consent to participate}

The research was ratified through the Ethics Committee of the FAH in HMU and after the Declaration of Helsinki.

\section{Consent for publication}

Not applicable.

\section{Competing interests}

The authors state unequivocally that there are no competing interests relating to this research, authorship, and/or publication.

Received: 15 November 2021 Accepted: 29 December 2021 Published online: 20 January 2022

\section{References}

1. Saeedi P, Petersohn I, Salpea P, et al. Global and regional diabetes prevalence estimates for 2019 and projections for 2030 and 2045: Results from the International Diabetes Federation Diabetes Atlas, 9th edition. Diabetes Res Clin Pract. 2019:157:107843.

2. Resnikoff S, Pascolini D, Etya'ale D, Kocur I, Pararajasegaram R, Pokharel GP et al. Global data on visual impairment in the year 2002. Bull World Health Organ. 2004:82(11):844-51.

3. Busik JV. Lipid metabolism dysregulation in diabetic retinopathy. J Lipid Res. 2021;62:100017.

4. Colhoun HM, Betteridge DJ, Durrington PN, Hitman GA, Neil HA Livingstone SJ, et al. Primary prevention of cardiovascular disease with atorvastatin in type 2 diabetes in the collaborative atorvastatin diabetes study (CARDS): multicentre randomised placebo-controlled trial. Lancet. 2004;364(9435):685-96. https://doi.org/10.1016/S0140-6736(04)16895-5.

5. Kang EY, Chen TH, Garg SJ, et al. Association of Statin Therapy with Prevention of vision-threatening diabetic retinopathy. JAMA Ophthalmol. 2019:137(4):363-71. https://doi.org/10.1001/jamaophthalmol.2018.6399.

6. Chou Y, Ma J, Su X, Zhong Y. Emerging insights into the relationship between hyperlipidemia and the risk of diabetic retinopathy. Lipids Health Dis. 2020;19(1):241 Published 2020 Nov 19.

7. Jepsen AM, Langsted A, Varbo A, Bang LE, Kamstrup PR, Nordestgaard BG. Increased remnant cholesterol explains part of residual risk of all-cause mortality in 5414 patients with ischemic heart disease. Clin Chem. 2016; 62(4):593-604. https://doi.org/10.1373/clinchem.2015.253757.

8. Bernelot Moens SJ, Verweij SL, Schnitzler JG, Stiekema LCA, Bos M, Langsted $A$, et al. Remnant cholesterol elicits Arterial Wall inflammation and a multilevel cellular immune response in humans. Arterioscler Thromb Vasc Biol. 2017;37(5):969-75. https://doi.org/10.1161/ATVBAHA.116.308834.

9. Joshi PH, Khokhar AA, Massaro JM, et al. Remnant Lipoprotein Cholesterol and Incident Coronary Heart Disease: The Jackson Heart and Framingham Offspring Cohort Studies. J Am Heart Assoc. 2016;5(5):e002765 Published 2016 Apr 29.

10. Castañer O, Pintó X, Subirana I, Amor AJ, Ros E, Hernáez Á, et al. Remnant cholesterol, not LDL cholesterol, is associated with incident cardiovascular disease. J Am Coll Cardiol. 2020;76(23):2712-24. https://doi.org/10.1016/j.ja cc.2020.10.008

11. Gabir MM, Hanson RL, Dabelea D, Imperatore G, Roumain J, Bennett PH, et al. The 1997 American Diabetes Association and 1999 World Health Organization criteria for hyperglycemia in the diagnosis and prediction of diabetes. Diabetes Care. 2000;23(8):1108-12. https://doi.org/10.2337/diaca re.23.8.1108.

12. Jacobson TA, Ito MK, Maki KC, Orringer CE, Bays HE, Jones PH, et al. National lipid association recommendations for patient-centered management of dyslipidemia: part 1--full report. J Clin Lipidol. 2015;9(2):129-69. https://doi. org/10.1016/j.jacl.2015.02.003

13. Zou LX. Sun L, Nicholas SB, Lu Y, K SS, Hua R. comparison of bias and accuracy using cystatin $C$ and creatinine in CKD-EPI equations for GFR estimation. Eur J Intern Med. 2020;80:29-34. https://doi.org/10.1016/j.ejim.2 020.04.044.

14. Expert Dyslipidemia Panel of the International Atherosclerosis Society Panel members. An international atherosclerosis society position paper: global recommendations for the management of dyslipidemia--full report. J Clin Lipidol. 2014;8(1):29-60.
15. Duman TT, Aktas G, Atak BM, Kocak MZ, Erkus E, Savli H. Neutrophil to lymphocyte ratio as an indicative of diabetic control level in type 2 diabetes mellitus. Afr Health Sci. 2019;19(1):1602-6. https://doi.org/10.4314/ahs.v1 9i1.35.

16. Wilkinson CP, Ferris FL 3rd, Klein RE, et al. Proposed international clinical diabetic retinopathy and diabetic macular edema disease severity scales. Ophthalmology. 2003;110(9):1677-82. https://doi.org/10.1016/S0161-6420(03 )00475-5.

17. Lin X, Ma P, Yang C, Wang J, He K, Chen G, et al. Dietary-induced elevations of triglyceride-rich lipoproteins promote atherosclerosis in the low-density lipoprotein receptor knockout Syrian Golden Hamster. Front Cardiovasc Med. 2021:8:738060. https://doi.org/10.3389/fcvm.2021.738060.

18. Pearson ER. Type 2 diabetes: a multifaceted disease. Diabetologia. 2019; 62(7):1107-12. https://doi.org/10.1007/s00125-019-4909-y.

19. Hattori S. Empagliflozin decreases remnant-like particle cholesterol in type 2 diabetes patients with insulin resistance. J Diabetes Investig. 2018;9(4):870-4 https://doi.org/10.1111/jdi.12781.

20. Zhao Q, Cheng YJ, Xu YK, Zhao ZW, Liu C, Sun TN, et al. Comparison of various insulin resistance surrogates on prognostic prediction and stratification following percutaneous coronary intervention in patients with and without type 2 diabetes mellitus. Cardiovasc Diabetol. 2021;20(1):190. https://doi.org/10.1186/s12933-021-01383-7.

21. Ohnishi H, Saitoh S, Takagi S, Ohata JI, Isobe T, Kikuchi Y, et al. Relationship between insulin-resistance and remnant-like particle cholesterol. Atherosclerosis. 2002;164(1):167-70. https://doi.org/10.1016/S0021-9150(02 )00057-6.

22. Bao YK, Yan Y, Wilson B, Gordon MO, Semenkovich CF, Rajagopal R. Association of Retinopathy and Insulin Resistance: NHANES 2005-2008. Curr Eye Res. 2020;45(2):173-6. https://doi.org/10.1080/02713683.2019.1659977.

23. Afari ME, Bhat T. Neutrophil to lymphocyte ratio (NLR) and cardiovascular diseases: an update. Expert Rev Cardiovasc Ther. 2016;14(5):573-7. https:// doi.org/10.1586/14779072.2016.1154788.

24. Kurtul BE, Ozer PA. Neutrophil-to-lymphocyte ratio in ocular diseases: a systematic review. Int J Ophthalmol. 2019;12(12):1951-8. https://doi.org/10.1 8240/ijo.2019.12.18.

25. Wang JR, Chen Z, Yang K, Yang HJ, Tao WY, Li YP, et al. Association between neutrophil-to-lymphocyte ratio, platelet-to-lymphocyte ratio, and diabetic retinopathy among diabetic patients without a related family history. Diabetol Metab Syndr. 2020;12(1):55. https://doi.org/10.1186/s13098020-00562-y.

26. Nordestgaard BG. Triglyceride-rich lipoproteins and atherosclerotic cardiovascular disease: new insights from epidemiology, genetics, and biology. Circ Res. 2016;118(4):547-63. https://doi.org/10.1161/CIRCRESA HA.115.306249.

27. Takahashi S. Triglyceride rich lipoprotein -LPL-VLDL receptor and Lp(a)-VLDL receptor pathways for macrophage foam cell formation. J Atheroscler Thromb. 2017:24(6):552-9. https://doi.org/10.5551/jat.RV17004.

28. Varbo A, Benn M, Tybjærg-Hansen A, Nordestgaard BG. Elevated remnant cholesterol causes both low-grade inflammation and ischemic heart disease, whereas elevated low-density lipoprotein cholesterol causes ischemic heart disease without inflammation. Circulation. 2013;128(12): 1298-309. https://doi.org/10.1161/CIRCULATIONAHA.113.003008.

29. Li Z, Shen Y, Chen Y, Zhang G, Cheng J, Wang W. High uric acid inhibits cardiomyocyte viability through the ERK/P38 pathway via oxidative stress. Cell Physiol Biochem. 2018;45(3):1156-64. https://doi.org/10.1159/000487356.

30. De Becker B, Coremans C, Chaumont M, et al. Severe Hypouricemia impairs endothelium-dependent vasodilatation and reduces blood pressure in healthy young men: a randomized, placebo-controlled, and crossover study. J Am Heart Assoc. 2019;8(23):e013130. https://doi.org/10.1161/JAHA.119. 013130

31. Nakata T, Ikeda S, Koga S, Yonekura T, Tsuneto A, Doi Y, et al. Randomized, open-label, cross-over comparison of the effects of Benzbromarone and Febuxostat on endothelial function in patients with hyperuricemia. Int Heart J. 2020;61(5):984-92. https://doi.org/10.1536/ihj.20-114.

32. Yu Y, Lan T, Wang D, Fang W, Tao Y, Li M, et al. The association of lipid ratios with hyperuricemia in a rural Chinese hypertensive population. Lipids Health Dis. 2021;20(1):121. https://doi.org/10.1186/s12944-021-01556-Z.

33. Yu D, Wang Z, Zhang X, Qu B, Cai Y, Ma S, et al. Remnant cholesterol and cardiovascular mortality in patients with type 2 diabetes and incident diabetic nephropathy. J Clin Endocrinol Metab. 2021:106(12):3546-54. https://doi.org/10.1210/clinem/dgab533. 
34. Jansson Sigfrids F, Dahlström EH, Forsblom C, Sandholm N, Harjutsalo V Taskinen MR, et al. Remnant cholesterol predicts progression of diabetic nephropathy and retinopathy in type 1 diabetes. J Intern Med. 2021;290(3): 632-45. https://doi.org/10.1111/joim.13298.

35. Chung YR, Park SW, Choi SY, Kim SW, Moon KY, Kim JH, et al. Association of statin use and hypertriglyceridemia with diabetic macular edema in patients with type 2 diabetes and diabetic retinopathy. Cardiovasc Diabetol. 2017; 16(1):4. https://doi.org/10.1186/s12933-016-0486-2.

36. Fujihara Y, Nakamura T, Horikoshi T, Obata JE, Fujioka D, Watanabe Y, et al. Remnant lipoproteins are residual risk factor for future cardiovascular events in patients with stable coronary artery disease and on-statin low-density lipoprotein cholesterol levels <70 mg/dL. Circ J. 2019;83(6):1302-8. https://doi.org/10.1253/circj.CJ-19-0047.

37. Lind M, Pivodic A, Svensson AM, Ólafsdóttir AF, Wedel H, Ludvigsson J. $\mathrm{HbA} A_{1 c}$ level as a risk factor for retinopathy and nephropathy in children and adults with type 1 diabetes: Swedish population based cohort study. BMJ. 2019:366:14894. https://doi.org/10.1136/bmj.|4894.

38. DCCT/EDIC Research Group, Nathan DM, Bebu I, Hainsworth D, Klein R, Tamborlane W, et al. Frequency of evidence-based screening for retinopathy in type 1 diabetes. N Engl J Med. 2017;376(16):1507-16. https://doi.org/10.1056/NEJMoa1612836.

39. Wen X, Zhou X, Chen D, Cheng J, Ji L. Association between non-alcoholic fatty liver disease and diabetes-related microvascular complications: A retrospective cross-sectional study of hospitalized patients. Endocr Pract. 2021; S1530-891X(21)00046-X.

40. Curovic VR, Suvitaival T, Mattila I, Ahonen L, Trošt K, Theilade S, et al. Circulating metabolites and lipids are associated to diabetic retinopathy in individuals with type 1 diabetes. Diabetes. 2020;69(10):2217-26. https://doi. org/10.2337/db20-0104.

41. Valgimigli M, Gragnano F, Branca M, Franzone A, Baber U, Jang Y, et al. P2Y12 inhibitor monotherapy or dual antiplatelet therapy after coronary revascularisation: individual patient level meta-analysis of randomised controlled trials. BMJ. 2021;373:n1332. https://doi.org/10.1136/bmj.n1332.

42. Cesaro A, Gragnano F, Calabrò P, Moscarella E, Santelli F, Fimiani F, et al. Prevalence and clinical implications of eligibility criteria for prolonged dual antithrombotic therapy in patients with PEGASUS and COMPASS phenotypes: insights from the START-ANTIPLATELET registry. Int J Cardiol. 2021;345:7-13. https://doi.org/10.1016/j.jcard.2021.10.138.

\section{Publisher's Note}

Springer Nature remains neutral with regard to jurisdictional claims in published maps and institutional affiliations.

Ready to submit your research? Choose BMC and benefit from:

- fast, convenient online submission

- thorough peer review by experienced researchers in your field

- rapid publication on acceptance

- support for research data, including large and complex data types

- gold Open Access which fosters wider collaboration and increased citations

- maximum visibility for your research: over $100 \mathrm{M}$ website views per year

At $\mathrm{BMC}$, research is always in progress.

Learn more biomedcentral.com/submissions 